\title{
Crescimento do cáudice e fenologia de Dicksonia sellowiana Hook. (Dicksoniaceae) no sul do Brasil
}

\author{
Jairo Lizandro Schmitt ${ }^{1,2,4}$, Paulo Henrique Schneider ${ }^{2}$ e Paulo Günter Windisch ${ }^{3}$
}

Recebido em 17/12/2007. Aceito em 23/10/2008

\begin{abstract}
RESUMO - (Crescimento do cáudice e fenologia de Dicksonia sellowiana Hook. (Dicksoniaceae) no sul do Brasil). No sul e sudeste do Brasil, a samambaia arborescente Dicksonia sellowiana Hook. é ainda extraída ilegalmente de remanescentes florestais para uso da capa fibrosa do seu cáudice, bem como para cultivo como planta ornamental. No presente trabalho, o crescimento do cáudice, a produção, expansão e senescência de frondes, bem como a formação e liberação de esporos de $D$. sellowiana foram estudados com base na observação de 37 plantas. Durante um período de um ano de observação, os cáudices cresceram, em média, $5,65 \mathrm{~cm}^{2}$ ano ${ }^{-1}$, sendo que a taxa de crescimento se correlacionou fortemente com a altura das plantas. As taxas de produção de frondes novas $\left(10,86\right.$ frondes ano $\left.^{-1}\right)$ e de senescência (10,54 frondes ano $\left.{ }^{-1}\right)$, similares, evidenciaram capacidade de manter um número de frondes estável, no ano. Apenas 14 indivíduos desenvolveram frondes férteis, sendo que a maioria das plantas produziu esporos no verão, liberando-os no inverno. A produção e liberação de esporos foram mais influenciadas pela temperatura e fotoperíodo do que pela precipitação.
\end{abstract}

Palavras-chave: auto-ecologia, fenologia, pteridófita arborescente, taxas de crescimento, xaxim

\begin{abstract}
Caudex growth and fenology of Dicksonia sellowiana Hook. (Dicksoniaceae) in Southern Brazil). In Southern and Southeastern Brazil, the tree fern Dicksonia sellowiana Hook. still is illegally extracted from remnants forests for the use of its fibrous caudex cover, as well as for cultivation as an ornamental plant. In the present study the caudex growth, frond production, expansion and senescence as well as the formation and release of spores have been studied based on the observation of 37 plants. During an observation period of one year, the caudexes grew at an average of $5.65 \mathrm{~cm}_{\text {year-1 }}^{-1}$ and the growth rate presented a strong correlation with the height of the plants. Similar frond production rate $\left(10.86\right.$ fronds year $\left.^{-1}\right)$ and senescence $\left(10.54\right.$ fronds year $\left.{ }^{-1}\right)$ evidenced the capacity of maintaining a stable number of fronds throughout the year. Only 14 individuals developed fertile fronds, most of them producing spores during the summer and liberating them during the winter. Production and release of spores were influenced more by temperature and photoperiod rather than by rainfall.
\end{abstract}

Key words: auto-ecology, growth rates, phenology, tree fern, "xaxim"

\section{Introdução}

A fenologia estuda a ocorrência de eventos biológicos cíclicos em função das mudanças climáticas (Morellato 2003), sendo que raramente as pteridófitas são consideradas em estudos fenológicos realizados nos trópicos (Mehltreter \& Palácios-Rios 2003), uma vez que a maioria deles enfoca as espécies arbóreas das comunidades florestais (Mantovani et al. 2003; Marques \& Oliveira 2004; Marchioretto et al. 2007). No entanto, em florestas úmidas, as pteridófitas encontram condições ótimas para apresentarem alta diversidade (Tryon 1985), sendo que no sub-bosque florestal, o crescimento e a fertilidade dessas plantas podem estar primariamente correlacionados com mudanças sazonais de temperatura e precipitação (Mehltreter 2006). Por outro lado, além dessas variáveis climáticas, Chiou et al. (2001) verificaram que o comprimento do dia pode influenciar eventos fenológicos em pteridófitas. Quando comparado com as angiospermas, o crescimento de pteridófitas de porte arborescente pode ser considerado lento, embora elas possam atingir muitos metros de altura no subbosque ou até ultrapassar o dossel florestal, apresentando apenas tecidos primários e condução de água através de traqueídes (Schmitt \& Windisch 2006a).

$\mathrm{Na}$ região neotropical, a partir dos anos 70, começaram os estudos pioneiros de auto-ecologia de pteridófitas arborescentes, destacando-se entre eles

\footnotetext{
1 Programa de Pós-Graduação em Qualidade Ambiental

2 Centro Universitário FEEVALE, Instituto de Ciências da Saúde, Laboratório de Botânica, RS 239, 2755, 93352-000 Novo Hamburgo, RS, Brasil

3 Universidade Federal do Rio Grande do Sul, Programa de Pós-Graduação em Botânica, Av. Bento Gonçalves 9500, 91501-970 Porto Alegre, RS, Brasil

4 Autor para correspondência: jairols@feevale.br
} 
aqueles com populações de Alsophila bryofila R.M. Tryon e de Cyathea arborea (L.) Sm. realizado por Conant (1976) e de Alspohila salvinii Hook. por Seiler (1981), na América Central. Posteriormente, foram realizados estudos sobre fenologia da fronde e/ou crescimento do cáudice de outras espécies de samambaias arborescentes (Tanner 1983; Ortega 1984; Seiler 1984; Bittner \& Breckle 1995; Arens 2001; Mehltreter \& García-Franco 2008), inclusive no Brasil meridional (Schmitt \& Windisch 2001; 2003; 2006a; b; 2007). Porém, poucos estudos fenológicos têm sido realizados com Dicksoniaceae neotropicais (Wick \& Hashimoto 1971; Walker \& Aplet 1994; Durand \& Goldstein 2001) ou de outras partes do mundo (Chiou et al. 2001). No Sul do Brasil, Dicksonia sellowiana Hook. (Dicksoniaceae) é a única espécie dessa família, sendo que existem poucos dados sobre o crescimento do cáudice (Sehnem 1978) e fenologia da fronde (Hoehne 1930) dessa espécie na literatura. Por outro lado, Rogge et al. (2000) estudaram a criopreservação, enquanto que Borelli et al. (1990), Filippini et al. (1999), Renner \& Randi (2004) e Suzuki et al. (2005) estudaram a germinação de esporos e desenvolvimento inicial de D. sellowiana.

Dicksonia sellowiana ocorre no sul do México, América Central e América do Sul, da Venezuela até a Colômbia, Bolívia, Paraguai, Uruguai, sudeste e sul do Brasil (Tryon \& Tryon 1982). A espécie é uma das mais notáveis dentre as plantas que caracterizam as florestas do Brasil meridional, em especial as florestas com araucária, sendo conhecida popularmente por xaxim. A espécie cresce em altitudes que variam de $60 \mathrm{~m}$, no Estado do Rio Grande do Sul, até 2.200 m na Serra do Itatiaia, Estado do Rio de Janeiro. D. sellowiana apresenta cáudice arborescente, ereto, de até aproximadamente $6 \mathrm{~m}$ de altura, envolvido por uma espessa bainha de raízes adventícias, ao longo de toda a sua extensão. As frondes apresentam até cerca de 2,40 m de comprimento, com estípites longos nos indivíduos jovens e sésseis a curtíssimo-peciolados nos adultos, lâminas bipinadopinatífidas a pinatissectas, com ápice agudo ou acuminado (Fernandes 2000). Até o passado recente, os cáudices dessa espécie foram extensivamente utilizados pelo homem para fabricação de vasos ou como substrato para o cultivo de orquídeas ou outras plantas ornamentais (Lorscheitter et al. 1999; Fernandes 2000), que encontram no xaxim um substrato excelente para seu crescimento. Em decorrência de sua exploração extrativista desordenada, associada à destruição do seu hábitat natural e à escassez de dados sobre o comportamento de suas populações, $D$. sellowiana foi incluída na lista de espécies da flora brasileira ameaçada de extinção (Santos 1992) e no apêndice II da Convenção
Internacional das Espécies da Flora e da Fauna Selvagens em Perigo de Extinção (CITES).

O presente estudo tem como objetivos determinar 1) taxas de crescimento do cáudice; 2) taxas de produção, expansão e senescência de frondes; e 3) período de produção e liberação de esporos de uma população de Dicksonia sellowiana, crescendo numa formação florestal do sul do Brasil. A sincronia e a correlação desses eventos fenológicos com temperatura, fotoperíodo e precipitação foram estudadas. O trabalho apresentado representa uma contribuição importante para a compreensão do ciclo de vida da espécie e fornece subsídios para o seu manejo e conservação.

\section{Material e métodos}

Área de estudo - O trabalho de campo foi desenvolvido numa formação florestal de aproximadamente 50 ha, localizada no município de Morro Reuter (29³1'S e $51^{\circ} 04^{\prime} \mathrm{W} ; 570 \mathrm{~m} \mathrm{s.n.)}$, na encosta inferior do nordeste do Estado do Rio Grande do Sul, Brasil. A vegetação local representa uma área de contato entre os limites da Floresta Estacional Semidecidual e Floresta Ombrófila Mista (Teixeira et al. 1986) e possui no estrato emergente Araucaria angustifolia (Bert.) O. Ktze. O solo da região é originado de basalto, raso a profundo, com razoáveis teores de matéria orgânica e alta fertilidade química, pertencente à classe dos chernossolos argilúvicos férricos e associados à neossolos litólicos eutróficos (Streck et al. 2002). O clima regional é do tipo Cfa, segundo a classificação climática de Köppen, ou seja, temperado úmido, com temperatura do mês mais quente superior a $22{ }^{\circ} \mathrm{C}$ (Moreno 1961). A caracterização local incluiu os dados de precipitação e temperatura que foram obtidos na estação meteorológica do município de Dois

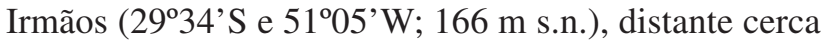
de $7 \mathrm{~km}$ do local de estudo. A medida astronômica padrão para a latitude foi proveniente do anuário interativo do Observatório Nacional (ON) disponível em http:// euler.on.br/ephemeris/index.php.

Crescimento do cáudice e fenologia - Em outubro/2003, foi iniciado o período de acompanhamento mensal do desenvolvimento de 37 indivíduos de Dicksonia sellowiana, que se estendeu até outubro/2004. Visitas adicionais anuais foram feitas em outubro/2005 e outubro/2006. As plantas foram marcadas utilizando-se estacas de madeira, numeradas, afixadas no substrato próximo ao cáudice. A altura foi mensurada do ápice do cáudice até o nível do solo, em outubro/2003 e, posteriormente, a intervalos de 12, 24 e 36 meses para determinar as taxas anuais de crescimento, a partir do incremento de altura das plantas. Os diâmetros da base 
(DB), da altura do peito (DAP) e do ápice (DA) foram obtidos apenas no primeiro censo. Os números de báculos, frondes maduras (totalmente expandidas com pinas verdes) e senescentes (com todas as pinas secas) foram contados, mensalmente, durante o primeiro ano de observação, para se obter a taxa de produção e de senescência de frondes. Báculos jovens foram marcados utilizando-se argolas de fio de náilon e o seu desenvolvimento foi acompanhado para se determinar taxas de expansão das frondes. O comprimento do estípite, da lâmina e comprimento total das frondes recém expandidas foram registrados. O número de frondes férteis e o período em que havia plantas com esporângios imaturos, completamente fechados e liberando esporos também foram registrados. O espécime testemunho da identificação foi depositado no Herbário Anchieta (PACA), em São Leopoldo, Rio Grande do Sul.

Análise estatística - Por meio do programa estatístico SPSS versão 15.0 , foi aplicado o teste de correlação de postos de Spearman para verificar as relações entre crescimento anual do cáudice; dimensões das frondes; produção, senescência foliar e média anual de frondes férteis com altura das plantas; produção, senescência foliar e média mensal de frondes maduras, bem como os eventos da fenologia de esporos com precipitação, temperatura média mensal e média mensal de comprimento do dia. Nessa analise, foram utilizados os valores dos erros, calculados conforme proposto por Santana \& Ranal (2006), de modo a evitar a interferência da grandeza das médias no resultado de correlação. Os valores de referência que qualificam as correlações foram adotados de acordo com Davis (1971): $r=0,01$ a 0,09 são correlações desprezíveis; $r=0,10$ a 0,29 são fracas; $r=0,30$ a 0,49 são moderadas; $r=0,50$ a 0,69 são fortes; $r=0,70$ a 0,99 são muito fortes; e $r=1,0$ indica correlação perfeita. Para comparar as taxas médias anuais de crescimento do cáudice, as médias de frondes maduras, bem como as variáveis climáticas (temperatura e precipitação) do triênio estudado, foi verificada a normalidade dos dados através do teste de Kolmogorov-Smirnov, enquanto que a homogeneidade das variâncias foi testada por meio do teste de Levene, ao nível de significância de 5\%. Nos casos em que as pressuposições foram satisfeitas, procedeu-se com a ANOVA, caso contrário, foi aplicado o teste de Kruskal-Wallis (Vieira 1980; Zar 1999). Para verificar a sincronia das fenofases na população, foi empregado o índice de sincronia ( $Z$ ) adaptado de Primack (1980) por Ranal \& Santana (2006). A sincronia é perfeita quando $Z=1$, ou seja, todos os indivíduos da população estão, simultaneamente, na mesma fenofase. Ao contrário, quando não ocorre nenhuma sincronia na população, $\mathrm{Z}=0$.

\section{Resultados}

Dados climáticos - Entre o período de outubro/2003 a setembro/2004, a temperatura média anual foi de $19,1^{\circ} \mathrm{C}$, sendo a média do mês mais quente (janeiro) de $23,8^{\circ} \mathrm{C}$ e a média do mês mais frio (maio) de $14,6{ }^{\circ} \mathrm{C}$ e precipitação acumulada de 1.398,6 mm. De outubro/2004 a setembro/2005, a temperatura média anual foi de $19,9^{\circ} \mathrm{C}$ e a precipitação acumulada de $1.776,3 \mathrm{~mm}$, enquanto que de outubro/2005 a setembro/2006, foi de $19,6{ }^{\circ} \mathrm{C}$ e $1.413,2 \mathrm{~mm}$, respectivamente. No triênio estudado, ocorreram, ocasionalmente, apenas três meses de seca (Fig. 1), uma vez que no Rio Grande do Sul o clima é úmido o ano inteiro (Buriol et al. 2007). De outubro/2003 a setembro/2004, a menor média mensal do comprimento do dia (fotoperíodo) foi registrada em junho, no inverno (Fig. 2).

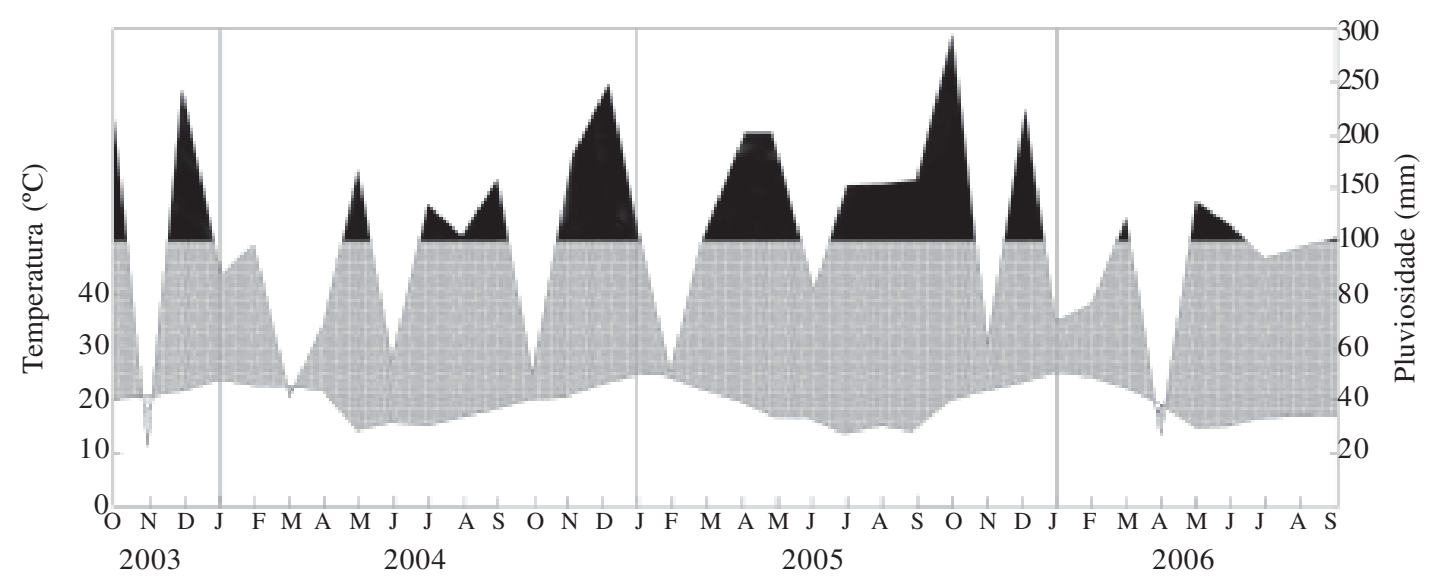

Figura 1. Diagrama meteorológico de outubro/2003 até setembro/2006. Dados registrados pela estação meteorológica do município de Dois Irmãos, RS, Brasil, distante cerca de $7 \mathrm{~km}$ do local de estudo. 


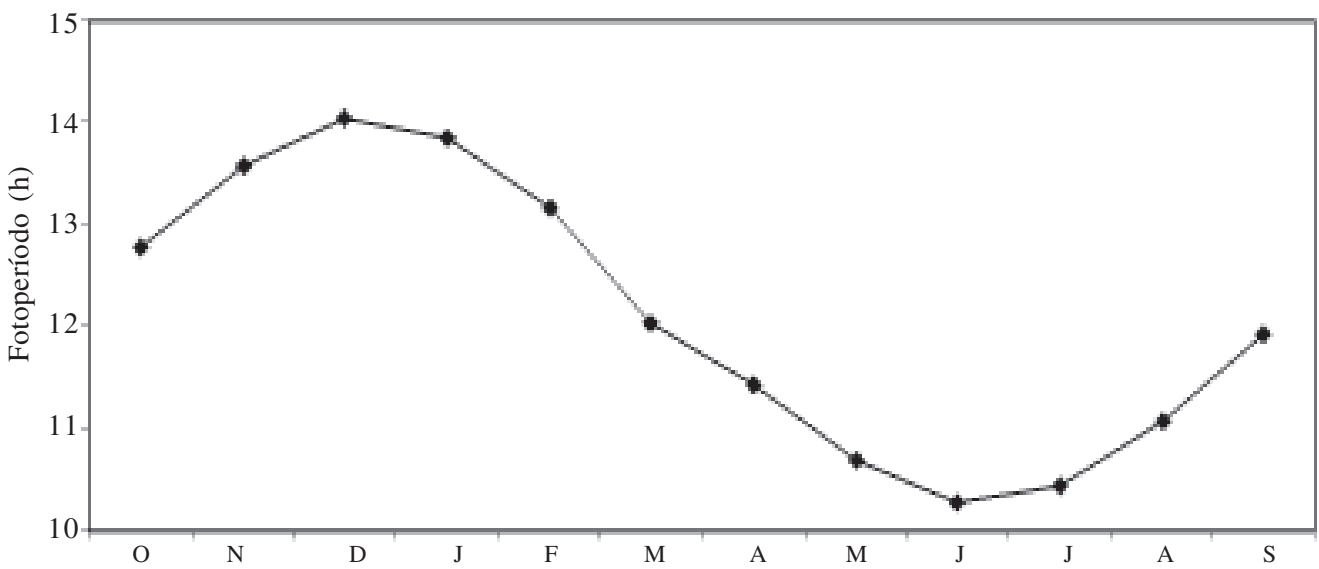

Figura 2. Média astronômica mensal de comprimento do dia (fotoperíodo), durante outubro/2003 a setembro/2004, em uma formação florestal do sul do Brasil.

Crescimento do cáudice - Em outubro/2003, entre as plantas marcadas, os cáudices de Dicksonia sellowiana apresentaram, no máximo, $246 \mathrm{~cm}$ de altura, $133 \mathrm{~cm}$ de diâmetro da base, $28 \mathrm{~cm}$ de diâmetro à altura do peito e $27 \mathrm{~cm}$ de diâmetro do ápice (Tab. 1). As plantas não apresentaram um incremento médio anual de altura significativamente diferente $(P=0,73)$, acompanhando as médias mensais de temperatura $(F=0,14 ; P=0,87)$ e a precipitação $(F=0,75 ; P=0,48)$ que também se mantiveram constantes, durante os três anos de estudo. O valor máximo de crescimento foi de $20 \mathrm{~cm}^{2} \mathrm{ano}^{-1}$, sendo registrado apenas no primeiro ano de observação (Tab. 2). Durante o triênio estudado, apenas três plantas não cresceram em altura. As taxas anuais de crescimento do cáudice correlacionaram-se fortemente com a altura no primeiro $(r=0,67, P<0,01, \mathrm{n}=37)$, segundo $(r=0,52$, $P=0,01, \mathrm{n}=37)$ e terceiro ano $(r=0,53, P=0,01$, $\mathrm{n}=37)$.

Fenologia da fronde - No máximo, as frondes mediram $295 \mathrm{~cm}$ de comprimento. O estípite e a lâmina apresentaram, respectivamente, até $106 \mathrm{~cm}$ e $278 \mathrm{~cm}$ de comprimento (Tab. 3). A altura do cáudice se correlacionou positivamente e fortemente com o comprimento da lâmina $(r=0,68, P<0,01, n=69) \mathrm{e}$

Tabela 1. Dimensões dos cáudices de Dicksonia sellowiana Hook. obtidos no primeiro censo (2003), em uma formação florestal do sul do Brasil. DB - Diâmentro da base; DAP - diâmetro à altura do peito; DA - diâmetro do ápice; $n$ - número de cáudices, DP - desvio padrão.

\begin{tabular}{lcccc}
\hline Dimensões & $n$ & $\begin{array}{c}\text { Mínimo } \\
(\mathrm{cm})\end{array}$ & $\begin{array}{c}\text { Máximo } \\
(\mathrm{cm})\end{array}$ & $\begin{array}{c}\text { Média } \pm \mathrm{DP} \\
(\mathrm{cm})\end{array}$ \\
\hline Altura & 37 & 30 & 246 & $107,35 \pm 56,41$ \\
DB & 37 & 13 & 133 & $29,69 \pm 19,75$ \\
DAP & 12 & 15 & 28 & $21 \pm 3,52$ \\
DA & 37 & 10 & 27 & $17,94 \pm 4,50$ \\
\hline
\end{tabular}

total da fronde $(r=0,62, P<0,01, n=69)$. O contrário foi observado entre altura e comprimento do estípite ( $r=-0,2, P=0,102, n=69)$. Os indivíduos de Dicksonia sellowiana produziram, em média, 10,86 $\pm 7,05$ frondes ano $^{-1}$, com amplitude entre 1 e 33 frondes ano ${ }^{-1}$. A renovação das frondes foi irregular, com a maioria delas sendo produzidas na primavera, com pico registrado no mês de novembro (Fig. 3), posteriormente a um período de alta precipitação e coincidindo com um aumento das temperaturas médias mensais e do fotoperíodo. Entretanto, não foram encontradas correlações significativas entre produção foliar e esses fatores climáticos. Em quatro meses do primeiro ano de observação, as plantas não produziram frondes, sendo que em outubro $22 \%$ e em novembro $70 \%$ dos indivíduos da população (Fig. 4) renovaram frondes, simultaneamente, refletindo num índice de sincronia $(Z)$ de 0,63

Tabela 2. Taxas mínima, máxima e média anual de crescimento do cáudice de Dicksonia sellowiana Hook., no período de 2003 a 2006, em uma formação florestal do sul do Brasil. DP - desvio padrão.

\begin{tabular}{cccc}
\hline Ano & $\begin{array}{c}\text { Mínimo } \\
\left(\mathrm{cm} \mathrm{ano}^{-1}\right)\end{array}$ & $\begin{array}{c}\text { Máximo } \\
\left.(\mathrm{cm} \mathrm{ano})^{-1}\right)\end{array}$ & $\begin{array}{c}\text { Média } \pm \mathrm{DP} \\
(\mathrm{cm} \mathrm{ano})\end{array}$ \\
\hline $1^{\circ}$ & 0 & 20 & $5,65 \pm 5,56$ \\
$2^{\circ}$ & 0 & 14 & $4,11 \pm 3,47$ \\
$3^{\circ}$ & 0 & 16 & $4,59 \pm 4,24$ \\
\hline
\end{tabular}

Tabela 3. Dimensões das frondes $(n=69)$ de Dicksonia sellowiana Hook. em uma formação florestal do sul do Brasil. DP - desvio padrão.

\begin{tabular}{lccc}
\hline Comprimento & $\begin{array}{c}\text { Mínimo } \\
(\mathrm{cm})\end{array}$ & $\begin{array}{c}\text { Máximo } \\
(\mathrm{cm})\end{array}$ & $\begin{array}{c}\text { Média } \pm \mathrm{DP} \\
(\mathrm{cm})\end{array}$ \\
\hline Estípite & 4 & 106 & $50,18 \pm 2,14$ \\
Lâmina & 54 & 278 & $166,66 \pm 12,93$ \\
Total & 101 & 295 & $216,85 \pm 49,81$
\end{tabular}


nesse período, enquanto que a sincronia anual foi menor e de $Z=0,22$. De uma maneira geral, as plantas mais altas produziram mais frondes durante esse ano $(r=0,52$, $P=0,01, n=37)$.

Em média, 69 báculos de Dicksonia sellowiana se expandiram mais rapidamente em outubro $(3,45 \pm$ $\left.1,14 \mathrm{~cm} \mathrm{dia}^{-1}\right)$ e novembro $\left(3,31 \pm 1,16 \mathrm{~cm} \mathrm{dia}^{-1}\right)$. Posteriormente, o aumento do comprimento da fronde foi muito mais lento, sendo em média de $0,28 \pm 0,31 \mathrm{~cm}$ dia $^{-1}$ em dezembro e de $0,001 \pm 0,003 \mathrm{~cm} \mathrm{dia}^{-1}$ em janeiro. No primeiro mês, foi registrada a taxa máxima de $3,45 \mathrm{~cm} \mathrm{dia}^{-1}$.

Em todos os meses do primeiro ano de observação, foram registradas plantas com senescência foliar sendo, em média, produzidas $10,54 \pm 6,26$, com amplitude entre 1 e 29 frondes senescentes ano ${ }^{-1}$. Embora a senescência foliar de Dicksonia sellowiana não tenha se correlacionado com variáveis climáticas, a maior média mensal ocorreu em novembro (Fig. 3), quando foi registrado o menor volume de chuvas e aumento do fotoperíodo. Nesse mês, foi registrada a maior freqüência de indivíduos da população (Fig. 4) com frondes senescidas $(68 \%)$, embora que esse evento fenológico tenha sido praticamente assincrônico $(Z=0,01)$, durante esse ano de observação. As taxas de senescência anual de frondes, de uma maneira geral, foram maiores em plantas mais altas $(r=0,52, P=0,01, n=37)$.

Nos primeiros 12 meses de observação, o número mínimo e máximo de frondes maduras por esporófito foi, respectivamente, zero e 46 . Nesse período, foi observada uma tendência de regularidade nas médias mensais do número de frondes maduras por planta (Fig. 3) e uma correlação forte com temperatura média mensal (Tab. 4). A espécie estudada apresentou manutenção do número de frondes não apenas no primeiro ano de observação, uma vez que as médias de frondes maduras dos meses de outubro/2003 (13,92 $\pm 7,2), 2004$ $(13,05 \pm 7,65), 2005(12 \pm 8,08)$ e $2006(15,43 \pm 9,12)$ foram estatisticamente iguais $(F=1,20, P=0,31)$.

Apenas $14(38 \%)$ plantas apresentaram frondes férteis, apresentando, no mínimo, cáudice de $0,62 \mathrm{~m}$ de altura. A altura das plantas correlacionou-se fortemente

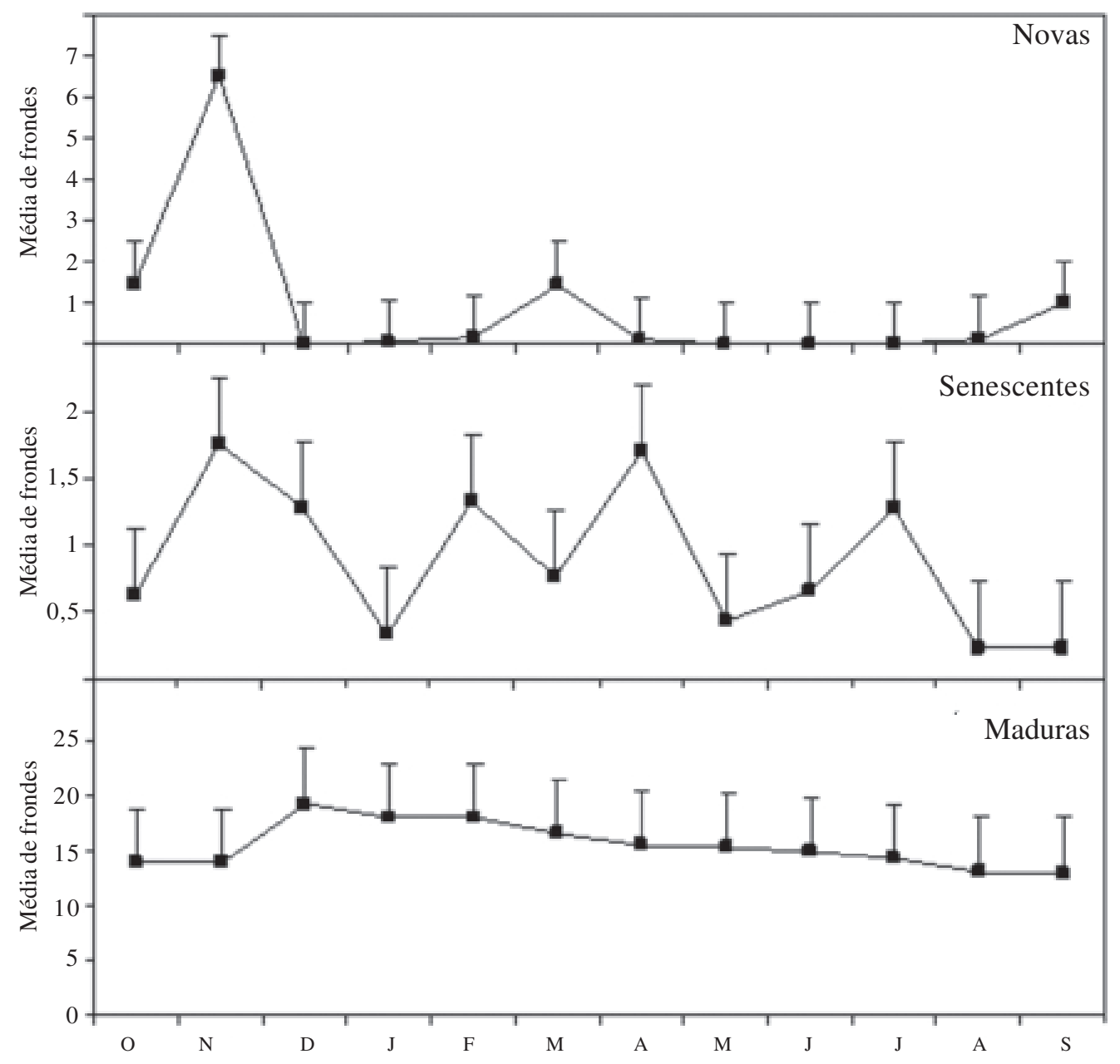

Figura 3. Média mensal de frondes novas, senescentes e maduras de Dicksonia sellowiana Hook., durante outubro/2003 a setembro/2004, em uma formação florestal do sul do Brasil. As barras indicam o desvio padrão. 


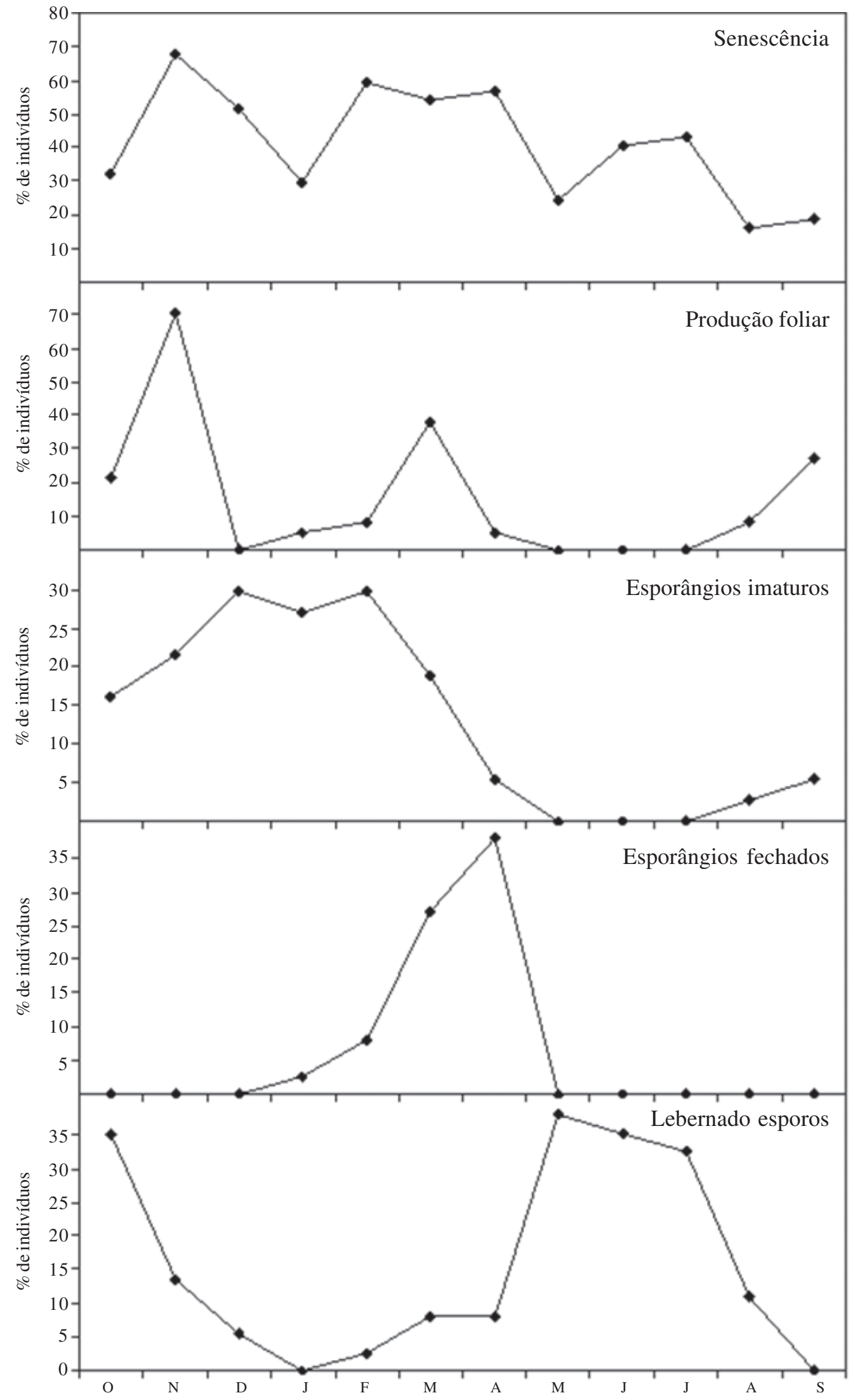

Figura 4. Porcentagem mensal de indivíduos de Dicksonia sellowiana Hook. apresentando senescência e produção foliar; frondes com esporângios imaturos, fechados e liberando esporos, durante outubro/2003 a setembro/2004, em uma formação florestal do sul do Brasil. 
Tabela 4. Correlações entre eventos fenológicos de Dicksonia sellowiana Hook. e variáveis ambientais, durante outubro/2003 a setembro/2004, em uma formação florestal do sul do Brasil.

\begin{tabular}{lccc}
\hline Evento & Temperatura $\left({ }^{\circ} \mathrm{C}\right)$ & Precipitação $(\mathrm{mm})$ & Fotoperíodo $(\mathrm{h})$ \\
\hline Produção de frondes & $0,37(P=0,24)$ & $-0,35(P=0,27)$ & $0,48(P=0,11)$ \\
Senescência de frondes & $0,28(P=0,38)$ & $-0,39(P=0,21)$ & $0,04(P=0,90)$ \\
Frondes maduras & $0,63(P=0,03)$ & $-0,03(P=0,91)$ & $0,02(P=0,95)$ \\
Produção de esporos & $0,90(P<0,01)$ & $-0,46(P=0,89)$ & $0,75(P<0,01)$ \\
Esporos fechados & $0,67(P=0,02)$ & $-0,32(P=0,31)$ & $-0,07(P=0,84)$ \\
Liberando esporos & $-0,74(P<0,01)$ & $0,06(P=0,84)$ & $-0,57(P=0,06)$ \\
\hline
\end{tabular}

com a média anual de frondes férteis $(r=0,68, P<0,01$, $n=37)$, sendo que o indivíduo mais alto da população $(2,46 \mathrm{~m})$ apresentou o número máximo de 20 frondes férteis, nos meses de dezembro e janeiro. Com exceção de maio, junho e julho, foram encontradas plantas produzindo esporos (com esporângios imaturos), durante todo o primeiro ano de observação com um índice de sincronia $(Z)$ de 0,13 . A maior frequiência de indivíduos $(n \geq 10$ ou $>70 \%)$ produzindo esporos nos meses de dezembro, janeiro e fevereiro (Fig. 4) refletiu num aumento do índice de sincronia $(Z=0,31)$ nesse período. A produção de esporos se correlacionou muito fortemente com temperatura e fotoperíodo. A freqüência das plantas apresentando frondes com esporângios fechados foi maior em março e abril ( $n \geq 10$ ou $>70 \%)$, refletindo numa sincronia maior durante esses dois meses $(\mathrm{Z}=0,49)$ quando comparada com a de todo o primeiro ano de observação $(Z=0,34)$. O número de indivíduos com esporângios fechados se correlacionou fortemente com temperatura (Tab. 4). A liberação de esporos ocorreu durante todo o ano, com exceção de janeiro e setembro. As maiores frequiências de indivíduos férteis liberando esporos foram registradas em outubro, maio, junho e julho (Fig. 4) ( $n \geq 12$ ou $>85 \%)$, resultando numa sincronia mais alta $(Z=0,32)$, durante os três últimos meses citados, de que àquela registrada durante todo o primeiro ano $(Z=0,13)$. A liberação de esporos se correlacionou negativamente e fortemente com temperatura (Tab. 4). Em uma mesma planta, enquanto que ocorria a liberação de esporos, parte dos esporângios estava imatura ou permaneceu fechada. De uma maneira geral, o período de maturação dos esporos foi de aproximadamente 120 dias.

\section{Discussão}

O crescimento médio do cáudice de Dicksonia sellowiana foi lento, relativamente constante, acompanhando as condições climáticas semelhantes, durante o triênio estudado. O incremento médio de altura da espécie estudada foi similar ao de outras espécies de Dicksoniaceae, tal como foi observado para Cibotium splendens (Gaud.) Krajina $\left(5 \mathrm{~cm}^{\mathrm{ano}} \mathrm{o}^{-1}\right)$ por Wick \& Hashimoto (1971), Cibotium glaucum (Smith) Hook. \& Arn. (5-7 $\left.\mathrm{cm} \mathrm{ano}^{-1}\right)$ por Walker \& Aplet (1994) e Cibotium chamissoi Kaulf. ( $\left.3 \mathrm{~cm}^{\mathrm{ano}} \mathrm{o}^{-1}\right)$ por Durand \& Goldstein (2001), no Havaí. As taxas de crescimento do cáudice de $D$. sellowiana também estão dentro da faixa de crescimento registrada para espécies arborescentes de Cyatheaceae do Rio Grande do Sul (Tab. 5). Considerando que o indivíduo mais alto da população tem aproximadamente $2,5 \mathrm{~m}$ e que o crescimento médio em altura no triênio estudado foi de $4,78 \mathrm{~cm}^{2} \mathrm{ano}^{-1}$, pode-se estimar que ele tenha 52 anos. Entretanto, essa estimativa não considerou o ciclo de vida completo desse indivíduo porque é desconhecido o tempo de estabelecimento do esporófito (com cáudice) a partir do gametófito. Além disso, estimativas que consideram cicatrizes foliares e produção anual de frondes são mais realísticas do que aquelas baseadas apenas em taxas de crescimento do cáudice e altura das plantas (Schmitt \& Windisch 2006a). Baseado na taxa de crescimento do

Tabela 5. Comparação de taxas de crescimento do cáudice de Dicksonia sellowiana Hook. com outras espécies arborescentes do Estado do Rio

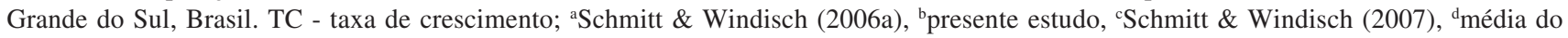
triênio.

\begin{tabular}{lccccc}
\hline Espécie & $\begin{array}{c}\mathrm{TC} \\
\left(\mathrm{cm} \mathrm{ano}^{-1}\right)\end{array}$ & Floresta & Coordenadas geográficas & $\begin{array}{c}\text { Altitude } \\
(\mathrm{m})\end{array}$ & $\begin{array}{c}\text { Precipitação } \\
(\mathrm{mm})\end{array}$ \\
\hline Alsophila setosa & $6,32^{\mathrm{a}}$ & secundária & $29^{\circ} 38^{\prime} \mathrm{S} ; 51^{\circ} 00^{\prime} \mathrm{W}$ & 570 & 2.138 \\
Dicksonia sellowiana & $4,78^{\mathrm{b}, \mathrm{d}}$ & secundária & $29^{\circ} 31^{\prime} \mathrm{S} ; 51^{\circ} 04^{\prime} \mathrm{W}$ & 570 & $1.529,4^{\mathrm{d}}$ \\
Cyathea delgadii & $4,65^{\mathrm{c}}$ & secundária & $29^{\circ} 433^{\prime} \mathrm{S} ; 50^{\circ} 58^{\prime} \mathrm{W}$ & 47 & $1.341,6$ \\
\hline
\end{tabular}


cáudice, a idade estimada para indivíduos de Alsophila setosa Kaulf. com $4 \mathrm{~m}$ de altura, crescendo num fragmento florestal próximo ao do presente estudo, foi de 27 anos, enquanto aquela que considerou cicatrizes foliares e produção anual de frondes foi de 22 anos (Schmitt \& Windisch 2006a). Comparando-se o crescimento das plantas dentro da população, indivíduos mais altos tendem a apresentar as maiores taxas de crescimento do cáudice, de produção de frondes, além de frondes com lâminas mais longas. Essa tendência também foi observada em Cyathea delgadii Sternb. (Schmitt \& Windisch 2007) e em Alsophila setosa, com exceção do comprimento da fronde (Schmitt \& Windisch 2003), no Estado do Rio Grande do Sul. Conseqüentemente, indivíduos mais altos tendem a apresentar as maiores áreas de superfície foliar, podendo interceptar mais luz e potencialmente fixar mais carbono. Nesse sentido, Lambers et al. (1998) destacaram que quando plantas crescendo em um mesmo hábitat são comparadas, aquelas com maior superfície foliar tendem a apresentar as maiores taxas de crescimento.

Hoehne (1930) destacou que as frondes de Dicksonia sellowiana brotam na primavera, sincronicamente, tal como registrado no presente estudo. Esse padrão sazonal também foi observado na produção foliar de espécies nativas do gênero Cibotium por Wick \& Hashimoto (1971), Walker \& Aplet (1994) e Durand \& Goldstein (2001), no Havaí. Em Taiwan, Cibotium taiwanense Kuo apresentou pico de produção foliar no início da primavera e durante o verão (Chiou et al. 2001). No Estado do Rio Grande do Sul, em localidades próximas ao do presente estudo e de clima semelhante, Schmitt \& Windisch (2006b) acompanharam a fenologia das frondes em populações de Alsophila setosa e observaram que as mesmas se desenrolaram também, sincronicamente, na primavera e que em alguns meses do ano não ocorreu produção de frondes, tal como em maio, junho e julho registrados no presente estudo. A sincronia na produção de frondes pode ser uma estratégia de escape à ação de herbívoros (Janzen 1975). Porém, o padrão sazonal na produção de frondes não é típico de todas as samambaias arborescentes do estado, sendo que Schmitt \& Windisch (2007) verificaram em Cyathea delgadii novas frondes sendo produzidas durante todo o ano, embora irregularmente.

A fenologia da produção de frondes não apresentou correlações significativas com as variáveis climáticas, indicando que fatores ambientais pouco sazonais na área de estudo exerceram pouca influência sobre o desenvolvimento das frondes. Além dos fatores climáticos, possivelmente processos endógenos da planta e pressões seletivas bióticas devem influenciar a fenologia das frondes de Dicksonia sellowiana. Nesse sentido,
Aide (1988) destacou que a pressão de herbívoros, predadores e competidores, entre outros, são determinantes da fenologia vegetal, em ambientes com pouca sazonalidade climática. Borchert (1980) também sugeriu que as mudanças ambientais são fatores secundários e que, primariamente, processos periódicos endógenos atuam sobre a reprodução e crescimento de espécies de plantas tropicais. O padrão de expansão de frondes muito rápido durante a maturação e, posteriormente, muito mais lento que ocorreu em Dicksonia sellowiana também foi registrado em Cyathea pubescens Mett. ex Kuhn. (Shreve 1914), Alsophila setosa (Schmitt \& Windisch 2006b) e C. delgadii (Schmitt \& Windisch 2007). Entretanto, esses autores registraram valor máximo de expansão de frondes de Cyathea pubescens $\left(4,94 \mathrm{~cm} \mathrm{dia}^{-1}\right)$, Alsophila setosa $\left(7,48 \mathrm{~cm} \mathrm{dia}^{-1}\right)$ e $C$. delgadii $\left(6,71 \mathrm{~cm} \mathrm{dia}^{-1}\right)$ maior daquele de $3,45 \mathrm{~cm} \mathrm{dia}^{-1}$ registrado para $D$. sellowiana.

A heterogeneidade de padrões individuais refletiu no menor índice de sincronia anual registrado e resultou em um padrão contínuo, embora irregular, de senescência foliar na população de Dicksonia sellowiana. $\mathrm{O}$ maior pico de frondes senescentes coincidiu com o maior pico de produção foliar, contribuindo para que apenas $2 \%$ dos indivíduos da população sofressem abscisão total de frondes. Por outro lado, Schmitt \& Windisch (2006b) registraram em Alsophila setosa abscisão total de frondes, coincidindo com baixas temperaturas e precipitação, em $9 \%$ dos indivíduos monitorados. Ao contrário do presente estudo, Walker \& Aplet (1994) observaram em Cibotium glaucum que a mortalidade das frondes foi altamente sazonal e que ocorreu vários meses após a expansão total das frondes novas. Ao contrário do registrado no presente estudo, Sharpe (1997) citou que a precipitação foi o fator principal que afetou o tempo de vida das frondes de Thelypteris angustifolia Willd., enquanto Chiou et al. (2001) destacaram que a temperatura parece influenciar mais a senescência foliar em $C$. taiwanense. Em espécies arbóreas tropicais existem evidências que o desencadeamento da queda e a renovação foliar estejam relacionados com o equilíbrio hídrico da planta (Reich $\&$ Borchert 1984) e mudanças no fotoperíodo (Wright $\&$ van Schaik 1994). O registro de que indivíduos mais altos de D. sellowiana apresentaram maior número de frondes senescentes e a falta de boa correlação com variáveis climáticas sugere que a senescência foliar esteja relacionada com tamanho-idade dos cáudices; bem como ao fato de que plantas mais altas produzem mais frondes que, provavelmente, acabam sendo mais expostas às condições de ressecamento de que as plantas menores, mais protegidas no sub-bosque florestal. Similarmente ao presente estudo, em Cyathea delgadii (Schmitt \& 
Windisch 2007) a altura das plantas se correlacionou com senescência e não demonstrou relação com precipitação.

Taxas anuais de produção foliar e de senescência praticamente iguais resultaram na manutenção do número de frondes de Dicksonia sellowiana durante o primeiro ano de acompanhamento. Além disso, as médias de frondes maduras iguais em outubro de cada ano de observação revelaram uma capacidade da espécie em manter o número de frondes durante um período mais longo de tempo. Similarmente ao registrado no presente estudo, Cibotium glaucum (Walker \& Aplet 1994), Alsophila setosa (Schmitt \& Windisch 2006b) e Cyathea delgadii (Schmitt \& Windisch 2007) mantiveram o número de frondes praticamente estável durante o ano. A ausência de correlação entre frondes maduras com precipitação e fotoperíodo decorreu possivelmente da ausência de período seco e do fato da população estar protegida da radiação excessiva, no sub-bosque florestal. Em decorrência da renovação de frondes estar concentrada na primavera, a média de frondes expandidas (maduras) aumentou nos meses subseqüentes, acompanhando o aumento das temperaturas médias mensais e refletindo na sua correlação com temperatura. Segundo Sato (1982), as baixas temperaturas têm um efeito restritivo na expansão das frondes de pteridófitas.

A correlação entre altura e frondes férteis de Dicksonia sellowiana indicou que o tamanho-idade do cáudice é um dos fatores que influenciou a fertilidade das plantas na população. A tendência de apenas indivíduos mais altos produzirem frondes férteis também foi observada em Cyathea lasiosora (Kuhn) Domin. por Young \& Leon (1989), no Peru; em Alsophila setosa por Schmitt \& Windisch (2005) e C. delgadii por Schmitt \& Windisch (2007), no sul do Brasil.

As plantas apresentaram esporângios imaturos, fechados e liberando esporos em períodos seqüenciais de sincronia mais alta de que aquela registrada para o total de 12 meses. A maioria das plantas produziu esporos, com uma sincronia mais elevada, no verão e correlacionada com temperatura e fotoperíodo, corroborando com as observações de Sato (1982) de que o frio pode restringir a produção de esporos. Em outras espécies de pteridófitas, tal como Polypodium latipes Langsd. \& Fisch., crescendo em mata mesófila semidecídua do Estado de São Paulo, o fotoperíodo pode ser essencial para desencadear a formação de esporângios (Ranal 1995). De maneira geral, um número maior de indivíduos liberou esporos em meses com temperaturas médias menores, sendo que durante o inverno foi observada sincronia mais alta na população. Ao contrário do presente estudo, Cibotium taiwanense liberou a maioria de seus esporos durante o verão. Entretanto, Farrar
(1976) observou que espécies de pteridófitas em Woodman Hollow, Iowa, continuam liberando alguns de seus esporos no decorrer do inverno. A ausência de correlação entre os eventos da fenologia de esporos com precipitação pode estar relacionada com ausência de restrição hídrica durante o ano. A temperatura e o comprimento do dia parecem ser mais importantes para a fenologia das plantas em locais onde é úmido o ano inteiro (Morellato et al. 2000; Marques \& Oliveira 2004). $\mathrm{O}$ fato da produção e liberação de esporos serem irregulares e ocorrerem praticamente durante todos os meses do ano evita que toda a produção seja perdida, no caso de ocorrência de um período desfavorável após sua liberação.

\section{Agradecimentos}

Ao Centro Universitário FEEVALE, pelo apoio financeiro e infra-estrutura disponibilizada; ao Sr. Tito Hennemann, por autorizar o trabalho de campo em sua propriedade; a Dra. Marli A. Ranal, pelo auxílio na realização das análises de sincronia e de correlação.

\section{Referências bibliográficas}

Aide, T.M. 1988. Herbivory as a selective agent on the timing of leaf production in a tropical understory community. Nature 336: $574-575$.

Arens, N.C. 2001. Variation in performance of the tree fern Cyathea caracasana (Cyatheaceae) across a sucessional mosaic in Andean cloud forest. American Journal of Botany 88: 545-551.

Bittner, J. \& Breckle, S.W. 1995. The growth rate and age of tree fern trunks in relation to habitats. American Fern Journal 85: $37-42$.

Borchert, R. 1980. Phenology and ecophysiology of tropical trees: Erytrina poeppigiana O.F. Cook. Ecology 61: 1065-1074.

Borelli, F.P.; Castro, C.E.F.; Mathes, L.A.F.; Tombolato, A.F.C. \& Nagai, V. 1990. Propagação de pteridófitas in vitro através de esporos. Bragantia 49: 206-209.

Buriol, G.A.; Estefanel, V.; Chagas, A.C. \& Eberhardt, D. 2007. Clima e vegetação natural do Rio Grande do Sul segundo o diagrama climático de Walter e Lieth. Ciência Florestal 17: 91-100.

Chiou, W.L.; Lin, J.C. \& Wang, J. 2001. Phenology of Cibotium taiwanense (Dicksoniaceae). Taiwan Journal for Science 16: 209-215.

Conant, D.S. 1976. Ecogeographic and systematic studies in American Cyatheaceae. Ph.D. Thesis. Cambridge, Harvard University, Mass.

Davis, J.A. 1971. Elementary survey analysis. Englewood. Prentice-Hall.

Durand, L.Z. \& Goldstein, G. 2001. Growth, leaf characteristics, and spore production in native and invasive tree ferns in Hawaii. American Fern Journal 91: 25-35.

Farrar, D.R. 1976. Spore retention and release from overwintering fern fronds. American Fern Journal 66: 49-52.

Fernandes, I. 2000. Taxonomia dos representantes de Dicksoniaceae no Brasil. Pesquisas Botânica 50: 5-26.

Filippini, E.C.P.; Duz, S.R. \& Randi, Á.M. 1999. Light and storage on the germination of spores of Dicksonia sellowiana (Pres1.) Hook., Dicksoniaceae. Revista Brasileira de Botânica 22: $21-26$. 
Hoehne, F.C. 1930. As plantas ornamentaes da flora brasílica e o seu papel como factores da salubridade publica, da esthética urbana e artes decorativas nacionaes. Boletim de Agricultura, Secretaria da Agricultura, Indústria e Comércio do Estado de São Paulo: 115-130.

Janzen, D. 1975. Behavior of Himenaea courbaril when its pre-dispersal seed predator is absent. Science 189: 145-147.

Lambers, H.; Poorter, H. \& van Vuren, M.I. 1998. Inherent Variation in Plants Growth: physiological Mechanisms and Ecological Consequences. The Netherlands, Backhuys Publishers.

Lorscheitter, M.L.; Ashraf, A.R.; Windisch, P.G. \& Mosbrugger, V. 1999. Sonder-Abdruck aus Palaeontographica Beiträge zur Naturgeschichte der Vorzeit. PartII. Pteridophyte spores of Rio Grande do Sul flora, Brazil. Stuttgart, E. schweizerbart'sche Verlagsbuchhandlung.

Mantovani, M.; Ruschel, A.D.; Reis, M.S.; Puchalski, A. \& Nodari, R.O. 2003. Fenologia reprodutiva de espécies arbóreas em uma formação secundária da floresta atlântica. Revista Árvore 27: 451-458.

Marchioretto, M.S.; Mauhs, J. \& Budke, J.C. 2007. Fenologia de espécies arbóreas zoocóricas em uma floresta psamófila no sul do Brasil. Acta Botanica Brasilica 21: 193-201.

Marques, M.C.M. \& Oliveira, P.E.A.M. 2004. Fenologia de espécies do dossel e do sub-bosque de duas florestas de restinga da Ilha do Mel, sul do Brasil. Revista Brasileira de Botânica 27: 713-723.

Mehltreter, K. \& Palacios-Rios, M. 2003. Phenological studies of Acrostichum danaeifolium (Pteridaceae, Pteridophyta) at a mangrove site on the Gulf of México. Journal Tropical Ecology 19: 155-162.

Mehltreter, K. 2006. Leaf phenology of the climbing fern Lygodium venustum in a semideciduous lowland forest on the Gulf of Mexico. American Fern Journal 96: 21-30

Morellato, L.P.C. 2003. Características dos Padrões Fenológicos em Florestas Estacionais Neotropicais Pp. 299-322. In: V. Claudino-Sales (org.). Ecossistemas Brasileiros: manejo e conservação. Fortaleza, Expressão Gráfica e Editora.

Morellato, L.P.C.; Talora, D.C.; Takahasi, A.; Bencke, C.C.; Romera, E.C. \& Ziparro, V.B. 2000. Phenology of Atlantic Rain Forest trees: a comparative study. Biotropica 32: 811-823

Moreno, J.A. 1961. Clima do Rio Grande do Sul. Porto Alegre, Secretaria da Agricultura.

Primack, R.B. 1980. Variation in the fenology of natural population of montane shrubs in New Zealand. Journal of Ecology 68: 849-862.

Ortega, F. 1984. Notas sobre la autecologia de Sphaeropteris sanilis (Kl) Tryon (Cyatheaceae) em el Parque Nacional El Ávila - Venezuela. Pittieria 12: $31-53$.

Ranal, M.A. 1995. Estabelecimento de pteridófitas em mata mesófila semidecídua do Estado de São Paulo. 3. Fenologia e sobrevivência dos indivíduos. Revista Brasileira de Biologia 55: 777-787.

Ranal, M.A. \& Santana, D.G. 2006. How and why to measure the germination process? Revista Brasileira de Botânica 29: 1-11.

Reich, P.B. \& Borchert, R. 1984. Water stress and tree phenology in a tropical dry forest in the lowlands of Costa Rica. Journal of Ecology 72: 61-74.

Renner, G.D.R. \& Randi, A.M. 2004. Effects of sucrose and irradiance on germination and early gametophyte growth of the endangered tree fern Dicksonia sellowiana Hook. (Dicksoniaceae). Acta Botanica Brasilica 18: $375-380$.

Rogge, G.D.; Viana, A.M. \& Randi, A.M. 2000. Cryopreservation of spores of Dicksonia sellowiana: An endangered tree fern indigenous to South and Central America. Cryoletters 21: 223-30.

Santana, D.G. \& Ranal, M. A. 2006. Linear correlation in experimental desing models apllied to seed germination. Seed Science \& Technology 34: 233-239.

Santos, A.A. 1992. Dicksoniaceae. Pp. 47-48. In: L.E. Mello Filho; G.V. Sommer \& A.L. Peixoto. (coord.). Centuria Plantarum Brasiliesium Exstintionis Minitata. Sociedade Botânica do Brasil.
Sato, T. 1982. Phenology and wintering capacity of sporophytes and gametophytes of ferns native to Northern Japan. Oecologia 55: 53-61.

Schmitt, J.L. \& Windisch, P.G. 2001. Prejuízos causados pela geada no desenvolvimento de Alsophila setosa Kaulf. (Pteridophyta, Cyatheaceae). Revista de estudos / Centro Universitário Feevale 24: 79-88.

Schmitt, J.L. \& Windisch, P.G. 2003. Relação entre comprimento do estípite, produção de frondes e tamanho do cáudice, em Alsophila setosa Kaulf. (Pteridophyta, Cyatheaceae). Pesquisas Botânica 53: 55-63.

Schmitt, J.L. \& Windisch, P.G. 2005. Aspectos ecológicos de Alsophila setosa Kaulf. (Cyatheaceae, Pteridophyta) no sul do Brasil. Acta Botanica Brasilica 19: $861-867$

Schmitt, J.L. \& Windisch, P.G. 2006a. Growth rates and age estimates of Alsophila setosa Kaulf. in southern Brazil. American Fern Journal 96: 103-111.

Schmitt, J.L. \& Windisch, P.G. 2006b. Phenological aspects of frond production in Alsophila setosa Kaulf. (Cyatheaceae: Pteridophyta) in southern Brazil. Fern Gazette 17: 263-270.

Schmitt, J.L. \& Windisch, P.G. 2007. Estrutura populacional e desenvolvimento da fase esporofitica de Cyathea delgadii Sternd. (Cyatheaceae, Monilophyta) no sul do Brasil. Acta Botanica Brasilica 21: 731-740.

Sehnem, A. 1978. Ciateáceas. Flora Ilustrada Catarinense. Itajaí. Herbário Barbosa Rodrigues.

Seiler, R.L. 1981. Leaf turnover rates and natural history of the Central American tree fern Alsophila salvinii. American Fern Journal 71: 75-81.

Shreve, F. 1914. A Montane Rain-Forest: A contribution to the physiological plant geography of Jamaica. Washington D.C., Carnegie Institution of Washington.

Sharpe, J.M. 1997. Leaf growth and demography of the rheophytic fern Thelypteris angustifolia (Willdenow) Proctor in a Puerto Rican rainforest. Plant Ecology 130: 203-212.

Seiler, R.L. 1984. Trunk length and frond size in a population of Nephelea tryoniana from El Salvador. American Fern Journal 74: 105-107.

Streck, E.V.; Kämpf, N.; Dalmolin, R.S.D.; Klamt, E.; Nascimento, P.C. \& Schneider, P. 2002. Solos do Rio Grande do Sul. Porto Alegre, EMATER/ UFRGS.

Suzuki, C.C.L.F.; Paulilo, M.T. \& Randi, A.M. 2005. Substrate and irradiance affect the early growth of the endangered tropical tree fern Dicksonia sellowiana Hook. (Dicksoniaceae). American Fern Journal 95: 115-125.

Tanner, E.V.J. 1983. Leaf demography and growth of tree-fern Cyathea pubescens Mett. ex Kuhn in Jamaica. Botanical Journal of the Linnean Society 87: 213-227.

Teixeira, M.B.; Coura Neto, A.B.; Pastore, U. \& Rangel Filho, A.L.R. 1986. Vegetação. Pp. 541-620. In: Levantamento de recursos naturais. v.33. Rio de Janeiro, IBGE.

Tryon, R. \& Tryon, A. 1982. Ferns and allied plants with special reference to Tropical America. New York, Springer Verlag.

Tryon, R.M. 1985. Fern speciacion and biogeography. Pp 353-360. In: A.F. Dyer \& C.N. Page (eds.). Biology of pteridophyte. Edimburg, The Royal Society of Edimburg.

Vieira, S. 1980. Introdução à bioestatística. $3^{\mathrm{a}} \mathrm{ed}$. Rio de Janeiro, Campus.

Walker, L.R. \& Aplet, G.H. 1994. Growth and fertilization responses of Hawaiian tree ferns. Biotropica 26: 378-383.

Wick, H.L. \& Hashimoto, G.T. 1971. Leaf development and stem growth of treefern in Hawaii. U.S. For. Serv. Res. Note PSW-237, Pacific Southwest For. and Range Expt. Sta., Berkeley, California.

Wright, S.J. \& van Schaik, C.P. 1994. Light and the phenology of tropical trees. The American Naturalist 143: 193-199.

Young, K.R. \& León, B. 1989. Pteridophyte species diversity the Central Peruvian Amazon: importance of edaphic specialization. Brittonia 41: 388-395.

Zar, J.H. 1999. Bioestatistical analysis. $4^{\text {th }}$ ed. New York, Prentice Hall. 